\title{
Slip control of deep-sea tracked miner during walking
}

\author{
Qing-jue HAN, Li-jun LI, Hui CHEN, Yue-can LI, Yue Wu, Ju-kun WANG, Si-yu HUANG \\ Department of mechanical and Electrical engineering, Central South University of Forestry and Technology \\ Changsha, Hunan, 410004, China
}

\begin{abstract}
By the analysis of the relationship between driving force from the sediments and slip rate and of the traction efficiency of the deep sea tracked miner, the optimal slip rate is determined. The fuzzy PID control strategy is put forward, and with the comparison of simulation results with and without control, the effectiveness of the control strategy is verified.
\end{abstract}

Keywords: Deep-sea, Tracked miner, Fuzzy control, Slip

\section{Introduction}

The deep-sea tracked miner, which walks on extremely cohesive sediment, is driven by the shear movement between miner and the soil. The driving force from the sediment is related to the slip rate of the miner during walking. Increase of slippage leads to reduction in the driving force, and this will directly affect the walking performance of the tracked miner. In order to make this tracked collecting machine better dynamic performance, the slip rate needs to be controlled in a certain range.

As for the slippage of tracked vehicles, a great number of studies have been carried out. Based on the data from the soil characteristic and the slip, Schiller had developed an parameter estimation method of the characteristic of the soil[1]. Since then, many method to estimate the slip rate have been addressed. Using enforced Kalman filter, the slip rate of the wheeled vehicles was estimated by Scheding[2]. Zweiri[3] and Buckholtz[4], using sliding mode controller, developed an slip control strategy of the wheeled vehicles. An nonlinear observer was put forward by Song to estimate slip rate in real time[5]. Chen had carried out a series of experiment to formulate real-time slip estimation method of the deep-sea tracked vehicle[6]. With the method of Kalman Filter, Dar had eliminate the noise, and accurately estimated the path, direction and slip rate of the tracked vehicle[7].

For the deep-sea tracked miner, a lot of experiments have been done. Ahmadi has done many studies on the analysis of the longitudinal slippage in the design of the path tracking control system[8]. A whole hydraulic mode of deep-sea tracked miner has been put forward by Schulte, and the slip control has been carried out[9].

\section{Driving Force of The Miner}

When the deep sea miner is walking on the sea floor, the traction force of the collector is limited by the condition of the sediment. The traction force should be consistent with the following formula:

$$
F_{d}=\frac{T_{m}}{r} \leq F_{n} \cdot \mu
$$

Here, $F_{d}$ is traction force; $T_{m}$ is the torque on the driving wheel; $F_{n}$ is the the normal force on the track; $u$ is the adhesion coefficient between the miner and the seafloor. Because the speed of the track alters with the torque, the greater the torque, the greater the speed of the track. The driving force provided by the soil has a maximum value. If the torque is too large, desired driving force will exceed the range of driving force that the soil can provide, therefore, the tracked miner will completely slip, which is very dangerous. In order to have good dynamic performance, the torque of the drive wheel should be adjusted to better control of the slip rate.

\section{Optimal Slip Rate}

Due to a function of shear stress and shear displacement, when the miner is walking on the extremely soft sediment, shear stress is produced by the shear displacement.The slip rate is defined as the following equation:

$$
i=1-\frac{v}{r \omega}=1-\frac{v}{v_{t}}=\frac{v_{t}-v}{v_{t}}=\frac{v_{j}}{v_{t}}
$$

In this equation, $v$ is the actual speed of the track; $v_{t}$ is the speed of the track determined by the angular velocity of the sprocket $\omega$, and the radius $\mathrm{r} ; v_{j}$ is the speed of the track relative to the ground. When the characteristics of the soil mechanics of the deep sea sediment, the optimal slip rate can be estimated after analysis of the relationship between driving force and slippage and of traction efficiency of the miner. The coefficient of adhesion in formula (1), is the effective driving force of the weight of the unit 


$$
\mu=\frac{F_{x}}{G}
$$

$F_{x}$ is the adhesion between the track and the seabed, $G$ is the adhesive weight. Meanwhile, the dynamic equation of the miner is:

$$
J \dot{\omega}_{L}=T_{m}-F_{x} \cdot r
$$

Here, $\mathbf{J}$ is rotational inertia of the drive wheel; $w_{L}$ is the rotational speed of the track. The formula (3) is substituted for (4):

$$
J \dot{\omega}_{L}=T_{m}-0.5 \cdot \mu \cdot G \cdot r
$$

So the adhesive coefficient can be expressed as:

$$
\mu=\frac{T_{m}-J \dot{\omega}_{L}}{0.5 \cdot G \cdot r}
$$

By derivation, we can get:

$$
\frac{d \mu}{d t}=\frac{\dot{T}_{m}-J \ddot{\omega}_{L}}{0.5 \cdot G \cdot r}
$$

The derivative of the slip rate can be obtained by derivation of formula (1):

$$
\frac{d i}{d t}=\frac{v r \dot{\omega}-r \omega \dot{v}}{r^{2} \cdot \omega^{2}}
$$

By combination of (7) and (8), we can get:

$$
\frac{d \mu}{d i}=\frac{d \mu}{d t} \cdot \frac{d t}{d i}=\frac{\dot{T}_{m}-J \ddot{\omega}_{L}}{0.5 \cdot G \cdot R} \cdot \frac{r^{2} \omega^{2}}{v r \dot{\omega}-r \omega \dot{v}}
$$

Obviously, there is a relationship between adhesive coefficient and slip rate. The optimum slip rate can be obtained by finding the maximum value of $u$. So the best slip ratio can be obtained by the cumulative method:

$$
i(t(k))=i(t(k-1))+\varepsilon \cdot \operatorname{sign}(d \mu / d t)
$$

\section{Slip Control System}

To ensure the walking performance of the miner during operation, a slip control system with fuzzy PID controller is designed. The whole system is composed of 5 subsystems, which are calculation module of optimum slip rate, the fuzzy PID control module, the hydraulic drive system module, the tracked miner module and the actual slip rate calculation module, respectively. The inputs of this system are the desired speed of miner and certain parameters of the soil, the output is the slip rate of the miner. The function and principle of each subsystem are as follows:

\subsection{Calculation module of optimum slip rate}

The optimum calculation module of slip rate is used to calculate the expected slip rate of the miner during walking, and the slip rate is used as the control target of the fuzzy PID controller.

When the needed parameters of soil are invariable, the best slip rate can be obtained by evaluating the relationship between the driving force and slip ratio as well as the traction efficiency. At this point, the input of the module is the expected speed $v_{d}=0.5 \mathrm{~m} / \mathrm{s}$ and soil mechanics parameters (which is shown in Table 4); When the parameters are not constant, the optimum slip ratio can be calculated using formula (10).

\subsection{Fuzzy PID controller module}

PID control strategy is advantageous because of simple structure, good stability, high reliability and so on. One of the key issues is the tuning of the PID parameter. Fuzzy PID control can optimize the proportion, integral and differential coefficients in real time, so as to achieve better control effect. The law of this PID control is:

$$
\begin{gathered}
u(t)=k_{p} e(t)+k_{i} \int e(t) d t+k_{d} \frac{d e(t)}{d t} \\
e(t)=i_{d}-i
\end{gathered}
$$

Here, $u(t)$, and $e(t)$ are system control quantity and deviation respectively; $k_{p}, k_{i}, k_{d}$ are scale coefficient, integral coefficient and differential coefficient.

Fuzzy PID controller, the control variable is slip rate $i$, the regulating variable is the input current $I$, which is the proportional valve in the hydraulic drive system. The controller takes the difference between actual slip rate of $i$ and desired slip rate $i_{d}$ as the error value $e_{i}$, and the error value and the error change rate are used as inputs of the controller. The control signal of the proportional valve serves as output to achieve the purpose of regulating the output torque and the motor speed. Slip rate deviation $e_{i}$ and deviation rate can be calculated in real time, and the parameters of PID controller can be adjusted according to fuzzy relation.

The input of the fuzzy PID controller is the deviation of the control variables $i$ and the change rate of the deviation, the output is the PID adjustment parameter $k_{p}, k_{i}, k_{d} . E$ and $E_{C}$ are fuzzy variable of $e_{i}$ and $\dot{e}_{i} ; K_{P}, K_{I}, K_{D}$ are fuzzy variable, and their domain of design is $\{-6,-5,-4,-3$, $2,-1,0,1,2,3,4,5,6\}$. Also its fuzzy sets are $\{\mathrm{PB}, \mathrm{PM}, \mathrm{PS}, \mathrm{Z}, \mathrm{NS}, \mathrm{NM}, \mathrm{NB}\}$. Among them, PB is positive big, $\mathrm{PM}$ is positive middle, $\mathrm{PS}$ is positive small, $\mathrm{Z}$ is zero, NS is negative small, NM is negative middle, and NB is negative big. The membership function curve of each fuzzy variable is shown in Figure 1. 


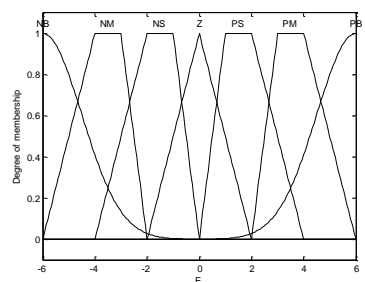

(a) variable $E$

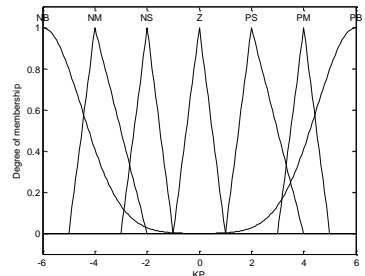

(c) variable $K_{P}$

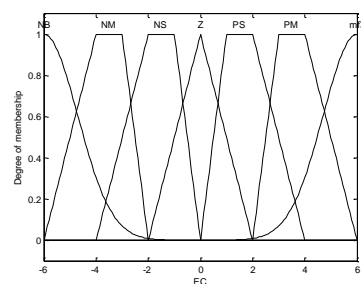

(b) variable $E C$

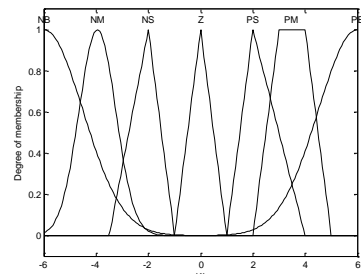

(d) variable $K_{I}$

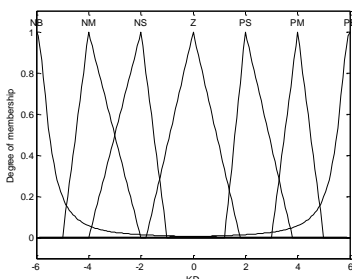

(E) variable $K_{D}$

Fig. 1 Membership function of each fuzzy variable.

In the fuzzy PID regulator, the fuzzy parameters of $K_{P}, K_{I}$, $K_{D}$ are derived from the control rules. The rules of control are shown in Table 1 to Table 3.

Table 1: Fuzzy rules of $K_{P}$

\begin{tabular}{|l|l|l|l|l|l|l|l|}
\hline E/EC & NB & NM & NS & Z & PS & PM & PB \\
\hline NB & PB & PB & PM & PM & PS & Z & Z \\
\hline NM & PB & PB & PM & PS & PS & Z & NS \\
\hline NS & PM & PM & PM & PS & Z & NS & NS \\
\hline Z & PM & PM & PS & Z & NS & NM & NM \\
\hline PS & PS & PS & Z & NS & NS & NM & NM \\
\hline PM & PS & Z & NS & NM & NM & NM & NB \\
\hline PB & Z & Z & NM & NM & NM & NB & NB \\
\hline
\end{tabular}

Table 2: Fuzzy rules of $K_{I}$

\begin{tabular}{|l|l|l|l|l|l|l|l|}
\hline E/EC & NB & NM & NS & Z & PS & PM & PB \\
\hline NB & NB & NB & NB & NM & NM & Z & Z \\
\hline NM & NB & NB & NM & NM & NS & Z & Z \\
\hline NS & NM & NM & NS & NS & Z & PS & PS \\
\hline Z & NM & NS & NM & Z & PS & PS & PM \\
\hline PS & NS & PS & Z & PS & PS & PM & PM \\
\hline PM & Z & Z & PS & PM & PM & PB & PB \\
\hline PB & Z & Z & PS & PM & PB & PB & PB \\
\hline
\end{tabular}

Table 3: Fuzzy rules of $K_{D}$

\begin{tabular}{|l|l|l|l|l|l|l|l|}
\hline E/EC & NB & NM & NS & Z & PS & PM & PB \\
\hline NB & PS & Z & Z & Z & Z & PB & PB \\
\hline NM & NS & NS & NS & NS & Z & PS & PM \\
\hline
\end{tabular}

\begin{tabular}{|l|l|l|l|l|l|l|l|}
\hline NS & NB & NB & NM & NS & Z & PS & PM \\
\hline Z & NB & NM & NM & NS & Z & PS & PM \\
\hline PS & NB & NM & NS & NS & Z & PS & PS \\
\hline PM & NM & NS & NS & NS & Z & PS & PS \\
\hline PB & PS & Z & Z & Z & Z & PB & PB \\
\hline
\end{tabular}

From Table 1 to Table 3, the fuzzy rule design principle is that in the case of $E$ larger, $P D$ control is adopted. This can speed up the response speed and quickly eliminate the steady-state error; In the case of moderate $E$, control accuracy is chosen as the main objective; In the case of smaller $E, K_{P}$ and $K_{D}$, take the big value to improve the stability of the system. The fuzzy inference output surfaces of $K_{P}, K_{I}, K_{D}$ are shown in Figure 2.

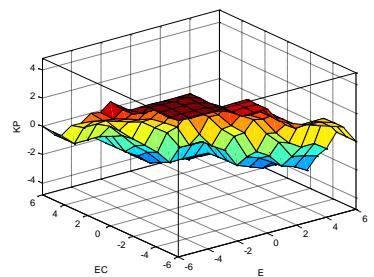

a) $K_{P}$ fuzzy inference surface

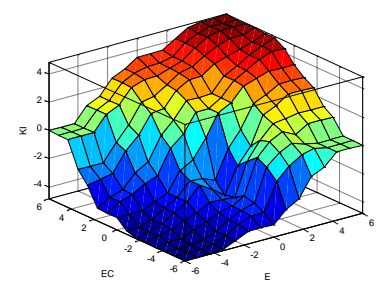

(b) $K_{I}$ fuzzy inference surface

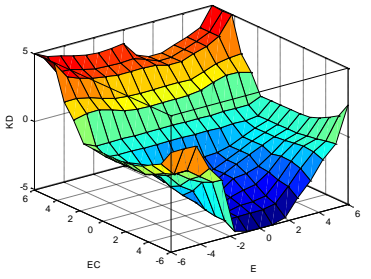

(c) $K_{D}$ fuzzy inference surface

Fig. 2 Output surface of fuzzy inference.

The corresponding fuzzy relation is expressed as follows:

$$
R_{l i j}=\left(E_{i} \times E C_{j}\right) \times K_{l}
$$

Accordingly, the corresponding fuzzy subsets can be obtained based on the measured values of $E$ and $E C$, the defuzzification was carried out by gravity center method. Finally, the parameters of the PID regulator $k_{p}, k_{i}, k_{d}$ are obtained.

\subsection{The real-time slip rate calculation module}

For the actual slippage rate calculation module, the actual input is set mining machine walking linear velocity, angular velocity of the driving wheel and the desired walking speed which is $0.5 \mathrm{~m} / \mathrm{s}$. According to slip rate when the miner is walking, compared with optimal slip rate in real time, the real-time deviation of slip rate is gotten, which serves as the input fuzzy PID controller.

The establishment of hydraulic drive system module and tracked miner module has been done in my previous work[10][11], which is not presented here. 


\section{Slip control simulation results and analysis}

When the miner is walking on the sediment, according to the soil mechanics characteristic parameters, the relationship between the optimum slip rate and the driving force can be seen, and the optimal slip rate is chosen as control target in the simulation. Based on the previous discussion, the desired slip rate is no more than 5\%. Figure 3 is the single-side miner slip control simulation model in MATLAB/simulink.

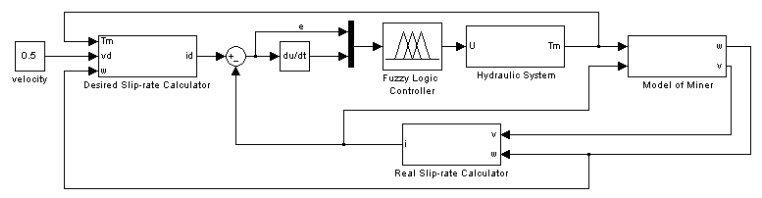

Fig. 3 Slip control simulation model.

According to mechanical properties of deep sea sediment in China, the soil mechanics properties changed little, so it can be regarded as homogeneous. For tracked miner, the relationship between the slip rate and driving force can be determined. Environment parameters in the simulation are shown in Table 4.

Table 4: Simulation parameters

\begin{tabular}{|c|c|}
\hline $\begin{array}{c}\text { The parameter name } \\
\text { the sormation modulus in }\left(\mathrm{k}_{\mathrm{c}}\right)\end{array}$ & The parameter value \\
\hline the & $5.715 \mathrm{KN} / \mathrm{m}^{(n+1)}$ \\
\hline Soil friction modulus(n) & $0.88 \mathrm{KN} / \mathrm{m}^{(n+2)}$ \\
\hline Subsidence index & 0.471 \\
\hline The initial value $K_{P}$ & 60 \\
\hline The initial value $K_{I}$ & 1 \\
\hline The initial value $K_{D}$ & 8 \\
\hline $\begin{array}{c}\text { Set the speed of the } \\
\text { collector }(V)\end{array}$ & $0.5 \mathrm{~m} / \mathrm{s}$ \\
\hline Expected slippage rate $\left(i_{d}\right)$ & $5 \%$ \\
\hline The simulation time $(t)$ & $2.5 \mathrm{~s}$ \\
\hline
\end{tabular}

The simulation results are shown in Fig. 4.

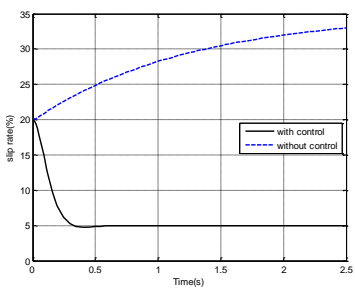

(a) Curves of slip rate

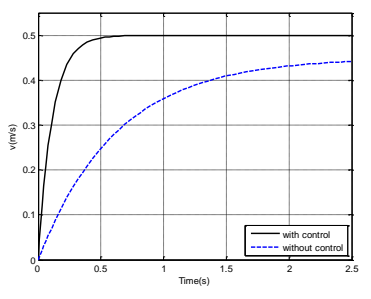

(b) Curves of theoretical speed

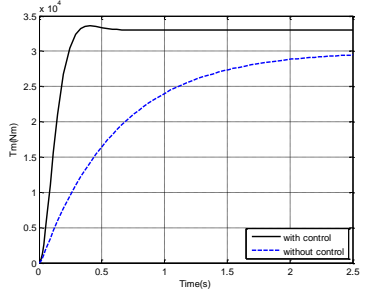

(c) curves of torque

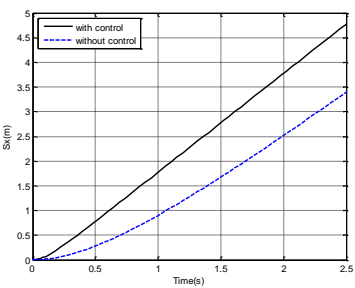

(d) curves of walking distance
Fig. 4 Simulation results of slip control system.

The real line of the graph is the simulation curve after control, and the dotted line is the simulation curve without control.

As can be seen from Fig. 4(a), the initial rate of slippage a is about 20\%. In the absence of control, the rate of slippage increases continuously with time, and the rate of slippage has reached $33 \%$ in 2.5 seconds. Therefore, without control, the miner will slip completely in a very short period of time, thus be trapped in the extremely soft sediment.

By the fuzzy PID slip control, the rate of slippage was reduced from $20 \%$ at start-up, to a minimum of 0.4 seconds, about $4.9 \%$. And at 0.6 seconds, it starts to stabilize at $5 \%$. Through simulation, it turns out that the fuzzy PID slip control strategy in this paper makes the miner better rapidity and stability, and meets the requirements of deep-sea tracked miner.

Fig. 4(b) shows the speed of the miner during simulation, Fig. 4(c) is about the the torque of driving wheel, and Fig. 4(d) is the walking distance. From Fig. 4(b), it can be seen that, with the same time, the speed with control is higher than speed without control, also the torque is higher. Consequently, the acceleration performance and dynamic performance of the miner is improved. Meanwhile, the walking distance of the miner is also clearly promoted.

\section{Conclusions}

1. Based on the relationship between the slip rate and driving force of the tracked vehicle, a method of calculation of optimal slip rate has been put forward.

2. A slip rate control strategy and relative control system have been established. The system consists of many modules, including slip calculation, Fuzzy PID controller, hydraulic driver, tracked miner, and real-time slip rate calculation.

3. A series of simulation of the deep-sea tracked miner during walking on homogeneous sediment has been done. By comparison of the results with and without control, the validity of the control strategy has been proved, thus the dynamic performance of the miner is improved. 


\section{Acknowledgments}

This work is financially supported by the science research project of The Education Department of Hunan Province of China.

\section{References}

[1] Schiller Z., Serate W., Hua M.. "Trajectory Planning of Tracked Vehicles" in IEEE International Conference on Robotics and Automation, 1993, 3,pp.796-801.

[2] Scheding S., Dissanayake G., Nebot E.M.. "An Experiment in Autonomous Navigation of an Underground Mining Vehicle" in IEEE Transactions on Robotics and Automation, 1999, 15,1, pp.85-95.

[3] Zweiri Y.H., Ehidborne J.F., Deneviratne L.D. "Diesel Engine Indicated and Load Torque Estimation using Sliding Mode Observer" in ASME 2000 ICE Fall Technical Conference, USA, pp. 24-27.

[4] Buckholtz K.R. "Wheel Slip Tracking Using Sliding Mode Control" in SAE 2002 World Congress, 2002, pp. 1-8.

[5] Song Z. , Hutangkabodee S. ,Zweiri Y.H. "Identification of Soil Parameters for Unmanned Ground Vehicles Trackterrain Interaction Dynamics" in SICE Annual Conference, 2004, 3, pp. 2255-2260.

[6] Feng C., Xiaoying H., Weihua G. "Slip Rate Estimation and Application Based on FSUKF for a Full Hydraulic Tracked Robot Vehicle" Journal of Acta Scientiarum Naturalium Universitatis Sunyatseni, 46,2, 2007, pp.199-203.

[7] Dar T.M., Longoria R.G. "Slip Estimation for Small-Scale Robotic Tracked Vehicles" in 2010 American Control Conference, USA, 2010, pp. 6816-6821.

[8] Ahmadi M., Polotski V., Hurteau R.. "Path Tracking Control of Tracked Vehicles" in the IEEE International Conference on Robotics and Automation, 2000, pp. 2938-2943.

[9] Herzog K. , Schulte E. , Atmanand M.A. "Slip Control System for a Deep-Sea Mining Machine", IEEE Transaction on Automation Science and Engineering, 2007, 4, 2, pp. 282-286

[10] Qing-jue H. "Slip and Path Tracking Control of the Deep Sea Tracked Miner", Ph.D. thesis, Department of Mechanical and Electrical Engineering, Central South University, Changsha, China, 2014.

[11] Qing-jue H., Shao-jun L. "Path Tracking Control of Tracked Vehicle", International Journal of Computer Science Issues, 10,6,1,2013, pp.103-109.

Qing-jue HAN has received PhD in 2014, the M.Sc in2006 and the B.Sc. in 2003 in the Department of Mechanical and Electrical Engineering from Central South University, China. Now he is a lecturer in Central South University of Forestry and Technology. His research interests focus on dynamics of tracked vehicles and off-road vehicles. Mr. Han is the membership of ASME and ISOPE, and has published many papers in the ISOPE(International Society Offshore and Polar Engineers). 